\title{
A PANDEMIA DO NOVO CORONAVÍRUS E A RESSIGNIFICAÇÃO DO FAZER PROFISSIONAL DO ASSISTENTE SOCIAL NA SAÚDE
}

\author{
THE PANDEMIC OF THE NEW CORONA VIRUS AND THE RESSIGNIFICATION OF \\ PROFESSIONAL DOING OF SOCIAL ASSISTANT IN HEALTH
}

DOI: http://dx.doi.org/10.16891/2317-434X.v8.e3.a2020.pp724-732

Recebido em: 06.07.2020 | Aceito em: 30.09.2020

\section{Gabriela do Nascimento Carvalho Silva*a, Antonio Fabio Alves Feitosa, Maria Karoline Dias dos Santos ${ }^{b}$, Maria Alves de Oliveirab, Mariana Piancó de Oliveirab}

\author{
Escola de Saúde Pública do Cearáa \\ PROJECTA/FACESA \\ *E-mail: gabrielacarvalho654@gmail.com
}

\section{RESUMO}

Diante das desigualdades e problemas sociais que vem se reconfigurando no cenário atual o Serviço Social é convidado a atuar nas mais diversas problemáticas societárias desencadeadas do processo dicotômico capital versus trabalho, com um vasto campo de atuação a saúde se mostra receptiva ao passo que são diversas as marchas sociais que interferem no processo saúde doença de uma dada população. A movimentação de inserção do Assistente Social na política pública de saúde tem se mostrado desafiadora ao passo que este profissional desencadeia um processo de materialização e reconhecimento tendo esse se exacerbado ainda mais diante da Pandemia do Novo Corona Vírus remetendo o profissional a nortear um posicionamento cada vez mais crítico a fim de desvelar e atuar nesta realidade de forma satisfatória e garantidora de direitos realocando suas dimensões ético político, técnica operativa e teórico metodológico para esta nova realidade. Com isso, o objetivo desta pesquisa se reflete na compreensão de como as transformações societárias tem recaimentos diretos ao profissional Assistente Social no contexto atual de saúde diante da pandemia onde uma nova dinâmica vem sendo recomposta os desafiando em seu processo de materialização e atuação. Esta foi desenvolvida diante de revisão bibliográfica referenciando autores como Costa (2000), Behring (2009), Iamamoto (2010), Santos (2020) remetendo-se ao entendimento da realidade e do processo concreto de trabalho do Assistente Social na saúde.

Palavras-chave: Saúde; Serviço Social; Coronavírus.

\section{ABSTRACT}

In view of the inequalities and social problems that have been reconfiguring in the current scenario, Social Work is invited to act on the most diverse corporate issues triggered by the dichotomous process capital versus work, with a wide field of action, health is receptive while there are several social marches that interfere in the health-disease process of a given population. The movement of insertion of the Social Worker in the public health policy has proved to be challenging as this professional unleashes a process of materialization and recognition, which has been exacerbated even more in the face of the Pandemic of the New Corona Virus, sending the professional to guide a position each time more critical in order to unveil and act in this reality in a satisfactory and guarantor of rights way, reallocating its political ethical, operational technical and methodological theoretical dimensions to this new reality. Thus, the objective of this research is reflected in the understanding of how the societal transformations have direct relapses to the professional Social Worker in the current health context in the face of the pandemic where a new dynamic has been recomposed, challenging them in their process of materialization and performance. This was developed in the face of a bibliographic review referring to authors such as Costa (2000), Behring (2009), Iamamoto (2010), Santos (2020) referring to the understanding of the reality and the concrete work process of the Social Assistant in health.

Keyword: Health; Social service; Coronavirus; 


\section{INTRODUÇÃO}

O vasto campo onde se encontra inserido o Serviço Social tendo em vista sua gênese atrelada a figura caritativa e dogmática da igreja católica dispõe de um legado imerso na caridade ensejando entre a filantropia e assistencialismo. Atualmente vários são os campos ao qual o Serviço Social se propõe a direcionar sua atuação intrinsicamente vinculada a luta de classe vagando entre a dicotomia capital versus trabalho.

Diante disso, considera-se a saúde um dos mais vastos campos de empregabilidade do Serviço Social, entrelaçando o desvelar dos processos sociais que interferem na dinâmica saúde doença vindo a impulsionar o trabalho do Assistente Social permitindo a reflexão profissional de inserção e materialização da profissão nas mais diversas entranhas estatais. Nisso o profissional percebe-se como mediador diante da tenção causada pela dicotomia capitalista tendo que trabalhar neste processo interventivo ao passo em que se reafirmar dentro deste ambiente visto a grande falha de se entender de fato o trabalho do mesmo dentro deste espaço.

Hoje o profissional Assistente Social diante da Pandemia do novo Corona Vírus (COVID-19) é convidado a assim como os demais profissionais atuantes na linha de frente a reinventar-se quer seja este inserido na atenção básica, média ou alta complexidade atuando nos determinantes que reconfiguram as expressões da "Questão Social" somando-se as já existentes, um processo contínuo de reafirmação que vem chamando o profissional a recompor-se diante de um Sistema Único de Saúde - SUS até então fragilizado impermeado de cortes vindo de um Estado neoliberal.

Considere-se este estudo de suma relevância tanto ao corpo profissional aqui categorizado e seus respectivos discentes bem como aos demais profissionais que compõe as mais variadas equipes estratégicas de efetivação do Sistema Único de Saúde, onde muitas vezes são perpassados de estigmas de reconhecimento profissional enquanto o fazer do Serviço Social, aspecto este exacerbado diante da pandemia do novo corona vírus diante das requisições dispostas pela própria figura estatal à categoria.

Assim, o objetivo desta pesquisa é entender a forma como o profissional de Serviço Social vem resinificando sua prática profissional imerso no SUS diante da pandemia do novo Corona Vírus, tendo que readaptar sua prática sem se perder no processo, alavancando uma ininterrupta materialização e afirmação de sua profissão neste espaço que por muitas vezes tanto confunde a categoria como a direciona a lacunas que não são suas.

Este será assentado nos pressupostos dos estudos sobre memória e literatura dos seguintes autores diante da explanação de sua linha de pensamento diante da temática, Costa (2000), Behring (2009), Iamamoto (2010), Santos (2020) dentre outros, bem como legislações que dispões de suporte para o aqui elucidado.

Foi desenvolvido em uma releitura bibliográfica que materializa a percepção do atual cenário de saúde onde o profissional de Serviço Social encontra-se imerso, sendo assim, estruturado e trazendo as seguintes reflexões: Breve contexto do Serviço Social e sua ligação com a saúde, uma breve estruturação da política de saúde pós Constituição Federativa do ano de 1988 e a inserção deste profissional na saúde a suas transfigurações em tempo de pandemia discutindo o que vem sendo posto, elencando e discutindo a prática profissional.

\section{DA ASSISTENCIA À SAUDE, UMA CONSTANTE BUSCA POR INSERÇÃO E MATERIALIZAÇÃO PROFISSIONAL}

Primordialmente, o trabalho do Assistente Social na área da saúde teve suas práticas alocadas na era de transformação e consolidação da sua profissão, estes atrelados a filantropia e a caridade possuíam seu trabalho subordinado a área médica atuando como suporte técnico. Um profissional meramente executor de demandas emergentes, onde trabalhar dessa forma não se exigia criticidade.

Diante do correr dos tempos e das mais variadas transformações societárias que chamam a figura do Estado a proporcionar um olhar a classe de trabalhadores que questionavam por mudanças torna-se relevante adequar sua inserção realocando a profissão para imersão nas políticas públicas, que emanam seu fazer profissional nas instituições públicas realocando seu trabalho a indivíduos, comunidades e famílias se desvinculando assim da filantropia e da caridade passando a refletir a cidadania e o direito público.

Refletindo a evolução deste serviço no tocante a sua inserção e materialização nas políticas públicas e assim na política de saúde, onde o acesso aos conhecimentos exercido na área sanitária passa a ser mediado diante dos Institutos de Aposentadorias e Pensões - IAPS, baseado em previdência social, em um período de industrialização assegurando os direitos dos trabalhadores de apenas determinadas classes sociais. Em 1938 surge o Conselho Federal de Serviço Social facilitando ainda mais os termos burocráticos diante da sociedade com isso propondo a vinculação com o Ministério da Educação e Saúde (BAPTISTA, 2007).

Várias são as transformações que elencam o Serviço Social a ser imerso em um viés político que os convidam a vislumbrar seu trabalho associado a uma prática profissional que enxerga uma constante ligação a classe trabalhadora e sua luta por garantia de direitos, o 
processo passa a requerer do profissional um olhar mais apurado passando este a atuar na dicotonomia capital versus trabalho sem se distanciar da sua real luta, a do trabalhador, inserido agora nas mais diversas instituições.

$\mathrm{Na}$ saúde onde a princípio surge como figura auxiliar passa a ganhar espaço próprio com delimitações do que é este profissional dentro deste serviço, garantir direitos e identifica as problemáticas sociais que interferem no processo saúde doença, ações totalmente divergentes das que conduziram sua gênese.

É com o fim do regime militar e a consolidação da Constituição Federal de 1988 no seu capítulo VIII da Ordem Social e na secção II referente à Saúde, coloca no artigo 196 que: "A saúde é direito de todos e dever do Estado, garantindo mediante políticas sociais e econômicas que visem a redução do risco de doença e de outros agravos e ao acesso universal e igualitário às ações e serviços para sua promoção, proteção e recuperação" (BRASIL,1988, p.118).

O SUS é definido no artigo 198, demonstra nitidamente uma visão de um modelo de saúde voltada para as necessidades da população, buscando readquirir o compromisso do Estado para com o bem-estar social, essas ações eram reflexo do momento político que passava a sociedade brasileira, recém saída de uma ditadura militar onde a cidadania nunca foi um princípio de governo (BAPTISTA, 2007).

O SUS se materializa por meio de uma soma de ações e serviços de saúde, realizados por órgãos e instituições públicas federais, estaduais e municipais, da administração direta e indireta e das fundações mantidas pelo Poder Público. Apesar de ter sido definido pela Constituição de 1988, somente foi regulamentado em 19 de setembro de 1990 através da Lei 8.080. Esta lei determina o modelo operacional do SUS, indicando a sua forma de organização e de funcionamento, também estabelece seus princípios e objetivos. Primeiramente a saúde passa a ser definida de uma forma mais abrangente:

\begin{abstract}
"A saúde tem como fatores determinantes e condicionantes, entre outros, a alimentação, a moradia, o saneamento básico, o meio ambiente, o trabalho, a renda, a educação, o transporte, o lazer e o acesso aos bens e serviços essenciais: os níveis de saúde da população expressam a organização social e econômica do país" (BRASIL, 1988, p. 20).
\end{abstract}

Ao defender essa concepção de saúde a reforma sanitária expressa a importância da determinação social sustentável nas variedades de trabalho e sua reprodução social, onde se encontra as expressões da questão social como retrata IAMAMOTO (1982) um conjunto das desigualdades da sociedade capitalista, que expressam por meio das determinações econômicas, políticas e culturais que impactam as classes sociais.

O SUS no seu percurso sofreu com as instabilidades institucionais e a desarticulação organizacional, escassez de financiamento, com a hegemonia da opção neoliberal no campo econômico, passa a buscava reconsiderar papel do estado e o seu peso na economia nacional, colocando ele para o chamado estado mínimo, na prática atingiu a todos os setores do governo, inclusive o da saúde e a área social.

Indo contra o que foi estabelecido na CF88, isentando o Estado das suas responsabilidades primordiais, onde interfere diretamente na vida dos sujeitos, fragilizando os setores públicos principalmente as políticas públicas, degradando o sistema de saúde e intensificando as expressões da questão social.

A questão social é ligada a sociabilidade da sociedade de classes e seus antagonismos constituintes, abrange um cenário de lutas políticas e culturais contra as desigualdades socialmente produzidas, ela se condensa nas múltiplas desigualdades mediadas por disparidades nas relações de gênero, características étnico-raciais, relações com o meio ambiente e formações regionais, atinge visceralmente a vida dos sujeitos numa luta aberta e surda pela cidadania (IANNI, 1992).

O serviço social cujo objeto de intervenção são as expressões multifacetadas da "Questão Social"1, encontra na saúde um campo da atuação valido e importante, visto como a saúde é tratada pelo Estado, e como reflete na vida dos sujeitos, e sua relacionada nas coisas que acontecem e definem a dignidade dos cidadãos.

\section{NAS ENTRELINHAS DA SAÚDE E DO SERVIÇO SOCIAL}

Historicamente a saúde tem sido o maior empregador de assistentes sociais. Desde os primórdios da profissão até o final da década de 1980, sua atuação neste campo se deu no âmbito curativo e por meio de abordagem individual. Após a redemocratização do país e, com a consolidação da Constituição Federal em 1988, a saúde foi uma das áreas onde houve avanços constitucionais mais significativos até então. O Sistema Único de Saúde, regulamentado em 1990, pela Lei Orgânica de Saúde (LOS), abriu novos espaços de atuação para os assistentes sociais na saúde,
${ }^{1} \mathrm{~A}$ “'Questão Social não é se não as expressões do processo de formação e desenvolvimento da classe operária e de seu ingresso no cenário político da sociedade exigindo seu reconhecimento como classe por parte do empresariado e do Estado. É a manifestação, no cotidiano da vida social, da contradição entre proletariado e a burguesia, a qual passa a exigir outros tipos de intervenção mais além da caridade e da repressão. (IAMAMOTO; CARVALHO 1995, p.77) 
principalmente no âmbito da gestão e planejamento da política, onde o profissional, juntamente com demais profissionais pode pensar em estratégias de melhoria do SUS.

Segundo Costa (2000), a inserção da categoria nos serviços de saúde é dada pelo reconhecimento social da profissão e pelo conjunto de necessidades que são redefinidas a partir das condições históricas que a saúde pública se desenvolveu no Brasil ao longo do tempo. Renomados autores vêm contribuindo nas últimas décadas com interessantes debates sobre o Serviço Social na saúde, dentre os quais destacam-se Maria Inês Bravo, Regina Célia Tamaso Mioto, Maria Dalva Horácio da Costa e o documento lançado pelo CFESS, sobre os Parâmetros para Atuação do Assistente Social na Saúde (2009), onde condensa o debate sobre Reforma Sanitária, o projeto ético-político profissional e sugestões de eixos para a prática do Serviço Social neste espaço.

Algumas resoluções são um marco para a inserção do profissional de Serviço Social na saúde. A exemplo disso, temos a resolução $n^{\circ} 218$, de 06 de março de 1997 do Ministério da Saúde, que reconhece a categoria de assistentes sociais como profissionais da saúde, e a resolução do CFESS, de no 393 de 29 de março de 1999, que também caracteriza o assistente social como profissional de saúde.

As atribuições e competências dos assistentes sociais, sejam elas realizadas na saúde ou em qualquer outro espaço sócio ocupacional são norteadas pelos direitos e deveres pré-estabelecidos no Código de ética e na lei de regulamentação da profissão, e que devem ser respeitados, tanto pelos profissionais quanto pelas instituições empregatícias.

De acordo com o documento feito pelo CFESS, com o objetivo de direcionar as intervenções dos assistentes sociais na saúde, a atuação dos mesmos, se faz diante de quatro eixos: "atendimento direto aos usuários; mobilização, participação e controle social; investigação, planejamento e gestão; assessoria, qualificação e formação profissional" (CFESS, 2009, p. 41).

Sobre o atendimento direto aos usuários, o texto ressalta que está atuação se dá em todos os espaços sócio ocupacionais de trabalho do assistente social, e se tratando da saúde, em especifico, este se concretiza desde atendimentos em unidades básicas, até a média e alta complexidade, passando pela atenção primária, Centros de Atendimento Psicossocial (CAP's), hospitais gerais, incluindo os universitários, a nível municipal, estadual e federal (CFESS, 2009).

Quanto as ações que caracterizam o atendimento direto aos usuários, são aquelas de cunho socioassistenciais e socioeducativas. E para realização de tal atuação, é imprescindível a investigação, planejamento e principalmente a participação dos usuários. As ações socioassistenciais têm-se constituído como as principais demandas postas aos profissionais de Serviço Social (CFESS, 2009).

As ações que devem ser desenvolvidas pelos assistentes sociais precisam ultrapassar o caráter emergencial e burocrático, característico dos serviços de saúde. Cabe ao profissional ter clareza das suas atribuições e competências estabelecidas nas normativas que norteiam o fazer profissional, afim de construir e estabelecer ações e estratégias, a partir das demandas apresentadas pelos usuários.

A avaliação econômica, assim como as visitas domiciliares, são importantes instrumentos utilizados por assistentes sociais, pois favorecem uma melhor compreensão da realidade social em que está inserido o sujeito, também não cabe ao profissional de Serviço Social utilizar no exercício de suas funções, as terapias individuais, de grupo, de família ou comunitárias, mas sim potencializar a orientação social com a finalidade de ampliação do acesso dos indivíduos e da coletividade aos direitos sociais.

Considera-se então, atribuições privativas do assistente social nos serviços de saúde, de acordo com o CFESS (2009):

Democratizar as informações por meio de orientações (individuais e coletivas) e /ou encaminhamentos quanto aos direitos sociais da população usuária; Construir o perfil socioeconômico dos usuários, evidenciando as condições determinantes e condicionantes de saúde, com vistas a possibilitar a formulação de estratégias de intervenção por meio da análise da situação socioeconômica (habitacional, trabalhista e previdenciária) e familiar dos usuários, bem como subsidiar a prática dos demais profissionais de saúde; Enfatizar os determinantes sociais da saúde dos usuários, familiares e acompanhantes por meio das abordagens individual e/ou grupal; Facilitar e possibilitar o acesso dos usuários aos serviços, bem como a garantia de direitos na esfera da seguridade social por meio da criação de mecanismos e rotinas de ação; Conhecer a realidade do usuário por meio da realização de visitas domiciliares, quando avaliada a necessidade pelo profissional do Serviço Social, procurando não invadir a privacidade dos mesmos e esclarecendo os seus objetivos profissionais; Conhecer e mobilizar a rede de serviços, tendo por objetivo viabilizar os direitos sociais por meio de visitas institucionais, quando avaliada a necessidade pelo Serviço Social; Elaborar estudos socioeconômicos dos usuários e suas famílias, com vistas a subsidiar na construção de laudos e pareceres sociais a perspectiva de garantia de direitos e de acesso 
aos serviços sociais e de saúde; Buscar garantir o direito do usuário ao acesso aos serviços; Emitir manifestação técnica em matéria de serviço social, em pareceres individuais ou conjuntos, observando o disposto na Resolução CFESS n ${ }^{\circ}$ 557/2009. E outros (CFESS, 2009, p. 44-45).

O trabalho em equipe também é tema que merece ser refletido, nos serviços de saúde, principalmente porque historicamente ao assistente social vem sendo requisito atribuições que não são de sua competência, seja pela equipe de saúde, seja pelas instituições empregadoras. Ao profissional, cotidianamente são requisitadas ações como: comunicação de óbito, marcação de exames, solicitação de medicamentos de alto custo, alta hospitalar, identificação de vagas em outras unidades de saúde para transferência de pacientes, dentre outras. Entretanto, essas ações de caráter puramente técnico-administrativo, não constituindo assim, como função dos assistentes sociais.

Assim, os assistentes sociais têm tido constantemente dificuldade de compreensão por parte da equipe de saúde acerca das suas atribuições e competências. Portanto, essas dificuldades devem incentivar a realização de reuniões e esclarecimentos sobre as ações e rotinas de trabalho do profissional, e fazer-se isso, quantas vezes forem necessárias, para que nos reconheçam como profissão necessária a política de saúde.

\section{A PANDEMIA DO NOVO CORONAVÍRUS E SEUS REBATIMENTOS À PROFISSÃO DO SERVIÇO SOCIAL}

O final do ano de 2019 para início de 2020 foi marcado por um intenso agravamento das desigualdades sociais no Brasil. Esse fator é decorrente devido ao surgimento de um novo vírus causador de uma doença altamente contagiosa. Essa desigualdade vem aprofundando as expressões da "Questão Social" e demandando forte intervenção do Assistente Social na viabilização de diretos da população.

O novo Corona Vírus recebeu a denominação SARS-COV-2 pela Organização Mundial da Saúde (OMS) e a doença que ele provoca tem a denominação COVID-19. Esta é uma doença respiratória identificada pela primeira vez em Wuhan, na China. Seus primeiros registros foram constados em 2019, mas a detecção do agente causador e as consequências dele ocorreram em 2020. A transmissão ocorre de uma pessoa para outra por meio do contato de gotículas respiratórias com muita facilidade (SANTOS, 2020).

Rapidamente esse vírus se espalhou pelo mundo e a Organização Mundial da Saúde (OMS) declarou, em 30 de janeiro de 2020, que o surto da doença causada pelo novo coronavírus (COVID-19) constitui uma emergência de saúde pública de importância internacional - o mais alto nível de alerta da Organização, conforme previsto no regulamento sanitário internacional. Em 11 de março de 2020, a COVID-19 foi caracterizada pela OMS como uma pandemia. Diante disso, torna-se de extrema importância debater acerca dos rebatimentos que essa pandemia vem causando no Brasil.

Ainda segundo a Organização Mundial da Saúde (OMS) e a Organização das Nações Unidas (ONU), a população pobre é a mais atingida por esse vírus, pois não possuem as condições necessárias indicadas como forma de prevenção, deixando em evidencia a desigualdade diante da pandemia. Os dados que vem sendo divulgados pela OMS mostram que a doença tem um índice de mortalidade relativamente baixo com relação ao número de casos, entretanto, esses dados recaem sobre aqueles indivíduos que estão em maior situação de vulnerabilidade econômica e social.

Com objetivo de prevenir a proliferação mais aguda, foi orientado pela Organização Mundial da Saúde (OMS) as seguintes ações de combate ao vírus: lavar as mãos com água e sabão ou higienizador à base de álcool para matar vírus, usar máscaras frequentemente caso for sair de casa, limpar bem os objetos de uso continuo, evitar o contato direto com outras pessoas e se resguardar em casa, manter um isolamento social rígido e procurar uma unidade de saúde apenas caso seja extremamente necessário para evitar superlotação nos hospitais (FIOCRUZ, 2020).

Isso remonta a discussões amplas que contestam essas recomendações ao analisar a desigualdade existente no Brasil. As recomendações de isolamento domésticos e de higienização ocorrem junto com o desemprego e subemprego, a falta de saneamento básico nas comunidades mais carentes, a falta de moradia para milhares de pessoas que vivem em situação de rua; com a falta de água e esgoto não dá a possibilidade necessária para as famílias seguirem as orientações exigidas (CFESS, 2020).

Vê-se então uma contradição na relação entre medidas recomendadas e possibilidades oferecidas pelo Estado para dar viabilidade a essas ações de proteção. A falta de política pública eficiente acaba deixando a população pobre mais vulnerável e possibilita ainda mais o agravamento da situação, já que no Brasil, maior parte da população vive em situação de pobreza.

Partindo para a situação de desigualdade dentro do sistema de saúde que vem sofrendo com as altas demandas devido a essa doença, pode-se analisas as condições que são dadas a população que requisita tais serviços em situação de urgência. Segundo o Conselho Federal de Medicina, (2018), o Brasil possuía quase 45 mil leitos de UTI, segundo informações do Cadastro 
Nacional de Estabelecimentos de Saúde. Pouco menos da metade $(49 \%)$ estava disponível para o SUS e a outra parte reservada exclusivamente à saúde privada ou suplementar (planos de saúde), que atendia $23 \%$ da população. Embora o número de leitos de UTI tenha aumentado nos últimos anos, a quantidade ainda é insuficiente, sobretudo no SUS, onde a demanda é crescente.

No contexto "normal" em que o Brasil vivia, isso já se apresentava como um grave problema. Já na situação atual, com a pandemia, isso ultrapassa qualquer possibilidade de efetivação de uma saúde de qualidade, em situação de universalização e democratização que é assegurada pela constituição à toda população.

Por dedução analítica, seguindo os dados citados acima de acordo com o Conselho Federal de Medicina, (2018), se $23 \%$ da população detinha $51 \%$ leitos, as outras $77 \%$ da população tinha que se satisfazer com os $49 \%$ restantes, ocasionando esgotamento rápido nos equipamentos devido à grande população do país. Vale ressaltar que esses dados foram registrados em 2018, entretanto, de lá para cá não houveram mudanças significativas nesse número até o surgimento da pandemia. Nesse sentido, esses dados recam como consequências no contexto atual.

Os dados que vem sendo divulgados acerca do Covid-19 pelo "Painel Corona vírus", atualizado diariamente pelas secretarias estaduais mostram que o primeiro caso da doença foi detectado no Brasil no dia 26 de fevereiro de 2020. A falta de investimentos e de medidas eficientes para o combate fizeram com que no dia 19 de junho de 2020 o país ultrapasse a marca de um milhão de casos, ou seja, em um intervalo de menos de quatro meses foram tomadas proporções drásticas. Enquanto vários países que viveram o colapso já adotam medidas mais flexíveis devido terem conseguido controlar a proliferação da doença a partir de medidas eficientes, o Brasil vem sendo apontado como o novo epicentro da pandemia no referido período mencionado acima (BRASIL, 2020).

É diante desse contexto de agravamento das desigualdades sociais que se vê a necessidade de intervenção do Assistente Social. No artigo $3^{\circ}$ do Código de Ética profissional consta que é dever do/a Assistente Social, na relação com a população usuária, "participar do programa de socorro a população em situação de calamidade pública, no atendimento e defesa de seus interesses e necessidades" (BRASIL, 1993).

Tendo ciência da necessidade de intervenção profissional nesse senário, faz-se necessário destacar também as possibilidades e os desafios que estão intrínsecos à prática da categoria do Serviço Social. Esses desafios não são problemas recentes. Eles estão presentes desde a institucionalização da profissão e vem se modificando de acordo com o contexto histórico.

Todos esses problemas que se apresentam como demandas para o Serviço Social são denominados de “expressões da questão social" e essas expressões são os objetos de intervenção da categoria, ou seja, o Serviço Social existe na medida em que há problemas sociais. IAMAMOTO, (1983) define "Questão Social" como o conjunto de expressões que surgem na sociedade capitalista e são contestadas pela classe trabalhadora.

Vale ressaltar que essas expressões se modificam com o período histórico na qual estamos inseridos, dessa forma, os profissionais devem sempre estar atentos para conseguir identifica-las e atuar de forma crítica frente as mesmas, não retrocedendo a uma prática conservadora nem realizar atribuições que não são próprias da profissão.

Com o surgimento da pandemia causada pelo Corona Vírus, as relações sociais sofreram grandes mudanças pelo aumento da desigualdade social. Com isso, novas demandas passaram a surgir e isso vem sendo pauta de várias discussões dentro da categoria para que os profissionais possam identificar as novas expressões e atuar de forma crítica e frente aos usuários que demandam dos seus serviços.

Um grave problema que vem sendo notado nesse contexto é a atribuição por parte do Estado e das instituições empregadoras de funções que não fazem parte das atribuições e competências profissionais instituídas na lei que regulamenta a profissão.

De acordo com o que está estabelecido na lei 8.662/1993 nos artigos $4^{\circ}$ e $5^{\circ}$ das competências e atribuições privativas o profissional deve elaborar, implementar, executar e avaliar políticas sociais junto a órgãos da administração pública; prestar orientação social a indivíduos, grupos e à população; orientar indivíduos e grupos de diferentes segmentos sociais no sentido de identificar recursos e de fazer uso dos mesmos no atendimento e na defesa de seus direitos; planejar, organizar e administrar benefícios e Serviços Sociais; planejar, executar e avaliar pesquisas que possam contribuir para a análise da realidade social e para subsidiar ações profissionais; entre outras (BRASIL, 1993).

Contrariando o que está posto nessa lei, o Conselho Federal de Serviço Social (CFESS) que é o órgão máximo responsável por orientar, disciplinar, normatizar, fiscalizar e defender o exercício da profissão em conjunto com os CRESS, lançou uma Orientação Normativa n. 3/2020, declarando que que estavam sendo atribuídas aos Assistentes Sociais o papel de comunicação de boletins de saúde e óbitos. Ainda segundo esse órgão, essas ações vão contra as condições éticas e técnicas para o exercício profissional que devem estar em consonância com a Resolução CFESS n. 


\section{3/2006 (CFESS, 2020).}

Visto isso, torna-se necessários que a categoria reafirme o seu verdadeiro papel na divisão sócio-técnica do trabalho para não retroceder ao tradicionalismo. Além dessas práticas reduzirem a papel político da profissão na sociedade, ela também viola os direitos dos cidadãos.

A família tem o direito de receberem informações precisas acerca do estado de saúde de seus parentes, bem como, em caso de óbito, saberem as reais causas (BRASIL, 1990). Nesse sentido, a comunicação de óbitos deve ser realizada por um profissional qualificado que tenha conhecimentos específicos acerca do caso clinico do paciente. Ao Assistente Social é dado o papel de trabalhar na garantia e efetivação de direito, socializando informações acerca de benefícios sociais e procedimentos legais que a família deve tomar em determinadas situações, atuar para que os direitos dos pacientes e das famílias não sejam violados e buscar o fortalecimento dos vínculos familiares.

Outro grande desafio que vem sendo notado é a falta de equipamentos apropriados para os Assistentes Sociais trabalharem garantindo a sua segurança. Por ter um trabalho que requer contato direto com os usuários, torna-se necessário a utilização de equipamentos de proteção individual (EPIs) seguros, entretanto, vários profissionais que estão atuando nessa linha de frente no combate a pandemia vêm afirmando que não estão sendo assegurados com tais equipamentos, colocando a sua saúde em risco pela falta de viabilização de direitos da própria categoria.

Esse desrespeito do Estado com os trabalhadores vai em consonância com o pensamento de IAMAMOTO, (2007) a autora afirma que os Assistentes Sociais são desafiados duplamente. Tanto como profissional que deve atuar para garantir os direitos dos cidadãos mesmo com a falta de políticas sociais e de recursos apropriados que garantam a emancipação dos sujeitos, como também, um profissional assalariado que tem os seus próprios direitos negligenciados. Vale ressaltar que no artigo $7^{\circ}$ do código de ética profissional é colocado que as instituições públicas ou privadas devem promover condições adequadas para garantia de um trabalho de qualidade no exercício profissional (BRASIL, 1993).

Diante das desigualdades e dos problemas que vem surgindo nesse cotidiano, o trabalho do Assistente Social torna-se tão essencial como os dos demais profissionais da saúde. Junto com a situação de calamidade na saúde, também se intensifica a violação de direitos, exigindo forte intervenção dessa categoria. A saúde não se desenvolve apenas no âmbito da cura, ela está principalmente na linha da prevenção, sendo que esta é influenciada por vários determinantes sociais. É nessa perspectiva que entra o papel do Assistente Social dentro dessa política. Para isso, ele deve ser capaz de decifrar toda essa realidade para não atuar apenas em correntes acríticas.

Segundo Iamamoto, (2000) é necessário atuar articulando as três dimensões da profissão: Teóricometodológica, ético-política e técnico-operativa. A não articulação dessas dimensões pode levar os profissionais a extremismos. É necessário romper com uma visão endógena e focalista para alargar os horizontes, a autora ainda afirma:

Um dos maiores desafios que o Assistente Social vive no presente é desenvolver sua capacidade de decifrar a realidade e construir propostas de trabalho criativas e capazes de preservar e efetivar direitos, a partir de demandas emergentes no cotidiano. Enfim, ser um profissional propositivo e não só executivo (IAMAMOTO, 2000, p. 20).

Diante de uma atuação crítica, os profissionais podem ser capazes de identificar todos os desafios que cercam sua prática e lutar diariamente para reafirmar o seu papel frente a sociedade e seu comprometimento com os cidadãos na garantia de direitos. Mesmo diante do processo de exclusão que estes profissionais sofrem dentro da política de saúde, eles devem mostrar a sua devida importância e seu verdadeiro fazer no contexto de pandemia e na vida cotidiana.

\section{CONSIDERAÇÕES FINAIS}

O campo de atuação do profissional de Serviço Social vem se amplificando ao passo que novas configurações societárias são expostas vindo a modificar a realidade trazendo uma série de ressignificações à sociabilidade transformando a forma de ver a política, a cidadania e o direito, colocando o Assistente Social a frente na mediação de diversas demandas, uma destas aqui tratada: a saúde.

A saúde tem sido um vasto campo de atuação, onde o profissional junto as equipes estratégicas sejam incorporadas na atenção básica, média ou alta complexidade vem desvelando problemáticas sociais que interferem direta ou indiretamente no processo saúde doença de uma dada população, problemáticas estas que podem ser pessoais, comunitárias ou em níveis mais abrangentes, alocando diante do seu fazer profissional percepções que possam em conjunto vislumbrar a ultrapassagem desta realidade.

Frente ao exposto conclui-se (entretanto não se encerra) que o campo saúde é extremamente desafiador para o Assistente Social, muitas vezes seu trabalho não é compreendido dentro da própria equipe diante do seu ser/fazer e que este fator decorre na sua grande maioria das vezes da sua própria figura empregadora em 
conformidade com aquilo que lhes é requisitado onde boa parte foge das suas reais competências e atribuições privativas profissionais.

Bem como diante do que seja e do que faz no âmbito desta política de forma geral, cabendo ao próprio profissional romper estas barreiras para materializar sua profissão e realizar seu trabalho de forma satisfatória neste ambiente de cuidados que requer um olhar singular a cada problemática que lhes exibem, resinificando o seu fazer de forma a estabelecer a real roupagem adquirida e reconhecida pela profissão.

Os rebatimentos da Pandemia do Novo Corona Vírus traz à tona a exacerbação do trabalho e este novo contexto cheio de transformações que ainda buscam ser entendidas convidam o Assistente Social a realizar aquilo que não é de sua competência e atribuição profissional tornando assim o cenário ainda mais desafiador onde além de manter uma compreensão de sociedade que venha estar perto das transformações sociais ainda manter uma leitura que não descaracterize sua profissão alavancando o diálogo do cuidado em saúde e da proteção social.

Dialogar e refletir entre teoria e prática no período de pandemia se torna atividade essencial para que o profissional possa manter sua linha de qualidade a qual se preconiza no seu próprio Código de Ética tendo que impermear-se diante dos moldes neoliberais e seus diversos processos impositivos de transformação sem perder a sua criticidade e compromisso societário e assim diante da Pandemia do novo Corona Vírus executar um trabalho que desvele a realidade e garanta direitos de todos os cidadãos.

A pandemia vem a esclarecer que muito ainda necessita ser transpassado, que o reflexo da sua figura profissional bem como o seu fazer na área da saúde necessitam ser trabalhados, esclarecidos e assim amplificados visando o enaltecimento da importância deste na incorporação dos serviços e na garantia dos direitos.

\section{REFERÊNCIAS}

BAPTISTA, Tatiana Wargas de Faria. História das Políticas de Saúde no Brasil: a trajetória do direito à saúde (capítulo 1 do livro: Políticas de saúde: a organização e a operacionalização do SUS). FIOCRUZ e Escola Politécnica de Saúde Joaquim Venâncio, 2007. Organizadores: Gustavo Corrêa Matta e Ana Lúcia de Moura Pontes.

BEHRING, E. Pensamento de Octavio Ianni. Um balanço de sua contribuição à interpretação do Brasil. Rio de Janeiro: Faperj/Centro de Estudos Octavio Ianni/7 Letras, 2009, p. 195-244.

BRASIL. Constituição (1988). CONSTITUIÇÃO DA REPUBLICA FEDERATIVA DO BRASIL: promulgada em 5 de outubro de 1988. 4.ed. São Paulo: saraiva, 1990.

BRASIL. CÓDIGO DE ÉTICA DO/A ASSISTENTE SOCIAL. Lei 8.662/93 de regulamentação da profissão. $10^{\mathrm{a}}$. ed. rev. e atual. - [Brasília]: Conselho Federal de Serviço Social, [2012].

BRASIL. LEI $\mathbf{N}^{\circ}$ 8.080, DE 19 DE SETEMBRO DE 1990. Dispõe sobre as condições para a promoção, proteção e recuperação da saúde, a organização e o funcionamento dos serviços correspondentes e dá outras providências.

Disponível em: http://www.planalto.gov.br/ccivil_03/leis/L8142.htm. Acesso em 26 de Julho de 2020.
BRAVO, Maria Inês [et al.], (organizadoras). Saúde e serviço social. 2. Ed - São Paulo : Cortez : Rio de Janeiro: UERJ, 2006.

CFESS. ORIENTAÇÃO NORMATIVA No. 3/2020.

Dispõe sobre ações de comunicação de boletins de saúde e óbitos por Assistentes Sociais. Disponível em: http://www.cfess.org.br/visualizar/menu/local/normativas -do-cfess. Acesso em 26 de Junho de 2020.

CFESS. Parâmetros para atuação de assistentes sociais na saúde. Brasília, 2009. Disponível em: http://www.cfess.org.br/arquivos/Parametros_para_Assist entes_Sociais_na_Saude_-_versao_preliminar.pdf. Acesso em 22 junho 2020.

COSTA, Maria Dalva Horácio da O. Trabalho nos serviços de saúde e a inserção dos(as) assistentes sociais. In: Serviço Social \& Sociedade. São Paulo: Cortez, $n^{\circ} 62,2000$.

CONSELHO NACIONAL DE SAÚDE Resolução nº 218, de 06 de março de 1997.

Resolução CFESS n ${ }^{\circ} 383$, de 29 de março de 1999. Caracteriza o assistente social como profissional de saúde. CONSELHO FEDERAL DE SERVIÇO SOCIAL (CFESS). Parâmetros para a Atuação de Assistentes Sociais na Saúde. Brasilia, 2009. Disponível em: 
http://www.cfess.org.br/arquivos/Parametros_para_a_Atu acao_de_Assistentes_Sociais_na_Saude.pdf Acesso: 23 jun 2020 às 13:56 hrs.

Conselho Federal de Medicina (CFM). MENOS DE $10 \%$ DOS MUNICÍPIOS BRASILEIROS POSSUEM LEITO DE UTI. Disponível em: https://portal.cfm.org.br/index.php?option=com_content \&amp;view=article\&amp;id=27828:2018-09-04-19-3141\&amp;catid=3. Acesso em 23 de Junho de 2020.

CORONAVÍRUS BRASIL. COVID-19. Disponível em: https://covid.saude.gov.br/. Acesso em 23 de Junho de 2020.

FIOCRUZ. CAMPANHA "SE LIGA NO CORONA!. Disponível em:

https://portal.fiocruz.br/es/coronavirus/perguntas-erespostas. Acesso em 23 de Junho de 2020.

IAMAMOTO. Marilda Villela. Relações sociais e serviço social no Brasil: esboço de uma interpretação histórico-metodológica/Marilda Villela Iamamoto, Raul de Carvalho-30 edição- São Paulo, Cortez; [Lima Pereira] : CELATS, 2010.

IAMAMOTO, Marilda Villela. O serviço social na contemporaneidade: trabalho e formação profissional. - 3 edição - São Paulo, Cortez, 2000.

IAMAMOTO, Marilda Villela. O SERVIÇO SOCIAL NA CONTEMPORANEIDADE: trabalho e formação profissional. $3^{a}$. ed. - São Paulo, Cortez, 2000.

IANNI, O. A Questão Social. In: A ideia do Brasil moderno. São Paulo: Brasiliense, 1992, p. 87-109.

. Enigmas do pensamento latino-americano. In: IAMAMOTO, M. V.;

IAMAMOTO, M. V.; CARVALHO, R de. Relações sociais e Serviço Social no Brasil. Esboço de uma interpretação históricometodológica. São Paulo: Cortez, 1982.

SANTOS, Vanessa Sardinha dos. CORONAVÍRUS (COVID-19); Brasil Escola. Disponível em: https://brasilescola.uol.com.br/doencas/coronaviruscovid-19.htm. Acesso em 24 de Junho de 2020. 